\title{
Factors influencing the prevalence of asthma among first degree relatives of extrinsic and intrinsic asthmatics
}

\author{
BONNIE SIBBALD AND MARGARET TURNER-WARWICK
}

From the Department of Medicine, Cardiothoracic Institute, Brompton Hospital, London, UK

\begin{abstract}
The prevalence of asthma, hay fever, and eczema was examined in first degree relatives of extrinsic (atopic) and intrinsic (non-atopic) asthmatics attending the asthma clinics of the Brompton Hospital and the Doncaster Royal Infirmary.

In both the Doncaster and Brompton populations the prevalence of asthma, hay fever, and eczema was significantly higher among relatives of extrinsic than among relatives of intrinsic asthmatics. Furthermore, the prevalence of these traits tended to be higher among siblings of extrinsic probands with one or both parents affected than among siblings of probands with neither parent affected. Most importantly, the prevalence of asthma among first degree relatives was positively correlated with the prevalence of hay fever or eczema or both among relatives and with the degree of atopy in the probands.

These findings are consistent with the results of previous investigations in which the expression of asthma was shown to depend on a genetic predisposition to the trait as well as exposure to environmental provoking agents. We further suggest that the presence of atopy in genetically predisposed individuals increases the risk of developing asthma.
\end{abstract}

Asthma may be defined as partial obstruction of airways that is reversible either in time or with treatment. Two broad forms of the disease are recognised. Extrinsic asthma, in which individuals are atopic, generally has an early age of onset (under 20 years) and boys are more often affected than girls (Williams and McNicol, 1969; Gregg, 1977). Intrinsic asthma, in which individuals are non-atopic, generally has a late age of onset (over 30 years) and the sex-ratio is even, or biased in favour of women (Gregg, 1977; Molina et al, 1977).

There is much evidence that asthma is partially hereditary in nature. Family studies have shown that the prevalence of asthma among relatives of asthmatic patients is significantly higher than it is among relatives of non-asthmatic patients (Leigh and Marley, 1967; Charpin and Arnaud, 1971; Gregg, 1977) and the risk of having an asthmatic child is significantly greater when one or both parents are asthmatic than when neither parent is affected (Charpin and Arnaud, 1971; Higgins and Keller, 1975). In addition, familial clustering in measures of forced expiratory volume in one second (Higgins and Keller, 1975) and in peak expiratory flow rate (Leeder et al, 1976) have been $\vec{F}$ reported, while twin studies have shown that the concordance rate is significantly higher in monozygotic than in dizygotic twins (Edfors-Lubs, 1971).

Although genetic studies on asthma have provided strong evidence for a hereditary component, $\frac{\text { 의 }}{3}$ the mode of inheritance has yet to be determined. The reason previous investigations have not re- -9 solved this problem may be partly the result of $\frac{D}{O}$ failing to differentiate between extrinsic and intrinsic forms of the trait. A comprehensive study ${ }_{\sigma}^{N}$ of asthma in families of extrinsic and intrinsic asthmatics was therefore begun, the preliminary results of which form the basis of this paper.

\section{Methods}

Probands were selected from patients attending $\stackrel{?}{?}$ the asthma clinics of the Brompton Hospital and $\frac{0}{-}$ the Doncaster Royal Infirmary during 1973-7. All $\stackrel{\odot}{\mathbb{D}}$ had a history of episodic wheeziness or breathless- $\stackrel{?}{?}$ ness and most showed reversible airways obstruc- $\stackrel{\triangleright}{\perp}$ tion either between successive visits or on treat- 
ment with a bronchodilator. Clearly atopic patients were selected as extrinsic probands and clearly non-atopic probands as intrinsic probands to increase the probability of detecting differences between these two forms of asthma. These probands were designated "polar."

Polar extrinsic probands had three or more positive skin prick tests of the 21 common allergens tested for. (Any weal of $2 \mathrm{~mm}$ or more in diameter in the absence of any equivalent reaction in the control tests was recorded as positive.) In addition, extrinsic probands had either a history of eczema or hay fever or both, or asthma provoked by pollens, dust, or animals. Only individuals whose age of onset was under 20 years were accepted. In contrast, polar intrinsic probands had no positive skin prick tests, no history of eczema or hay fever, and no asthma provoked by pollens, dust, or animals. Only individuals whose age of onset was over 30 years were accepted. Most asthmatics do not meet these criteria for polar intrinsic or polar extrinsic asthma. Individuals in this intermediate category have been described in detail and will be discussed in a later paper (Sibbald, in preparation). To give a more complete view of the asthma spectrum we now describe our findings in a sample of these asthmatic patients. Probands were selected from outpatients attending the Brompton clinic, and were classified into two groups that we have termed non-polar intrinsic asthma and intermediate type asthma.

Non-polar intrinsic asthmatics were skin test negative and had no allergic provoking factors. Unlike the polar group, however, they possessed one or both of the following factors: age of onset under 30 years; a positive history of hay fever or eczema or both. Intermediate asthmatics had either one or two positive skin prick test reactions; no other criteria were imposed when selecting these probands.

Information on the first degree relatives of probands was taken from an asthma questionnaire completed by a doctor on the proband's first visit to the clinic. For each proband the following information was recorded: total number of siblings and offspring, the number with asthma, hay fever or eczema or both; number of parents with asthma, hay fever or eczema or both; and sex of affected relatives.

The chi-square test was used to assess differences between groups (Mulholland and Jones, 1968). The P-values for one degree of freedom have been given except where otherwise indicated.

\section{Results}

In most respects the Brompton and Doncaster populations were similar (table 1). There were no measurable differences between Brompton and Doncaster extrinsic probands or between Brompton and Doncaster intrinsic probands. In addition, the prevalences of asthma, hay fever, and eczema among the first degree relatives of intrinsic asthmatics did not differ between the two populations. The prevalences of these traits, however were higher among relatives of Brompton extrinsic asthmatics than among relatives of Doncaster extrinsic asthmatics.

The data were analysed separately in the

Table 1 Comparison of Doncaster and Brompton populations

\begin{tabular}{|c|c|c|c|c|c|}
\hline \multirow[t]{2}{*}{ Character } & \multicolumn{2}{|c|}{ Doncaster } & \multicolumn{2}{|c|}{ Brompton } & \multirow[t]{2}{*}{ Significance } \\
\hline & Value & Percent & Value & Percent & \\
\hline $\begin{array}{l}\text { Extrinsic asthma } \\
\text { Probands } \\
\text { Proportion in sample } \\
\text { Sex-ratio } \mathrm{M}: \mathrm{F} \\
\text { Proportion with hayfever/eczema } \\
\text { No relatives/proband }\end{array}$ & $\begin{array}{c}119 / 379 \\
0 \cdot 83 \\
86 / 119 \\
5 \cdot 4\end{array}$ & $\begin{array}{l}31 \cdot 4 \\
\frac{72 \cdot 3}{-}\end{array}$ & $\begin{array}{c}208 / 787 \\
1 \cdot 12 \\
163 / 208 \\
4 \cdot 1\end{array}$ & $\begin{array}{l}26 \cdot 4 \\
\overline{78} \cdot 4 \\
-\end{array}$ & $\begin{array}{l}\text { NS } \\
\text { NS } \\
\text { NS } \\
\text { NS }\end{array}$ \\
\hline $\begin{array}{l}\text { First degree relatives } \\
\text { Prevalence of asthma } \\
\text { Prevalence of hay fever } \\
\text { Prevalence of eczema }\end{array}$ & $\begin{array}{l}67 / 639 \\
44 / 639 \\
28 / 639\end{array}$ & $\begin{array}{r}10 \cdot 5 \\
6 \cdot 9 \\
4 \cdot 4\end{array}$ & $\begin{array}{r}132 / 858 \\
134 / 858 \\
69 / 858\end{array}$ & $\begin{array}{r}15 \cdot 4 \\
15 \cdot 6 \\
8 \cdot 0\end{array}$ & $\begin{array}{l}P<0.05 \\
P<0.01 \\
P<0.05\end{array}$ \\
\hline $\begin{array}{l}\text { Instrinsic asthma } \\
\text { Probands } \\
\text { Proportion in sample } \\
\text { Sex-ratio } \mathbf{M}: \mathbf{F} \\
\text { No relatives/proband }\end{array}$ & $\begin{array}{l}26 / 379 \\
0 \cdot 73 \\
7 \cdot 2\end{array}$ & $\begin{array}{l}6.9 \\
-\end{array}$ & $\begin{array}{l}63 / 787 \\
0 \cdot 66 \\
7 \cdot 0\end{array}$ & $\begin{array}{l}8 \cdot 0 \\
-\end{array}$ & $\begin{array}{l}\text { NS } \\
\text { NS } \\
\text { NS }\end{array}$ \\
\hline $\begin{array}{l}\text { First degree relatives } \\
\text { Prevalence of asthma } \\
\text { Prevalence of hay fever } \\
\text { Prevalence of eczema }\end{array}$ & $\begin{array}{l}9 / 187 \\
1 / 187 \\
2 / 187\end{array}$ & $\begin{array}{l}4 \cdot 8 \\
0 \cdot 5 \\
1 \cdot 1\end{array}$ & $\begin{array}{r}19 / 439 \\
9 / 439 \\
5 / 439\end{array}$ & $\begin{array}{l}4 \cdot 3 \\
2 \cdot 0 \\
1 \cdot 1\end{array}$ & $\begin{array}{l}\text { NS } \\
\text { NS } \\
\text { NS }\end{array}$ \\
\hline
\end{tabular}


Brompton and Doncaster populations. The relative differences between extrinsic and intrinsic asthmatics in prevalences of asthma, hay fever, and eczema were similar in the two populations. In addition, the populations did not differ in the distribution of asthma either among parents, siblings, and offspring or among siblings of asthmatic patients with neither, one, or both parents affected.

This high degree of similarity between the two populations suggested that the factors precipitating asthma were probably common to both. Therefore we have combined the populations and have presented the results for the pooled data.

\section{POLAR EXTRINSIC PROBANDS}

Among the 1166 patients examined, $327(28 \cdot 0 \%)$ fulfilled the criteria for polar extrinsic asthma. Of these, 164 were men. The prevalence of hay fever did not differ between the sexes, while eczema was slightly more common among male than female probands (table 2 ).

The prevalence of asthma, hay fever, and eczema among the first degree relatives of the $\vec{F}$ polar extrinsic probands is summarised in table $3 . \stackrel{9}{9}$ The prevalence of asthma among parents, siblings, and offspring was not evenly distributed; $\frac{\bar{\sigma}}{\bar{N}}$ there were more affected parents and fewer af- $\frac{\vec{\phi}}{\vec{D}}$ fected siblings than expected.

The prevalence of asthma among siblings of $\&$ probands with neither, one, or both parents affected $\vec{\circ}$ tended to increase as the number of asthmatic parents increased (table 4). The lowest prevalence $\vec{\omega}$ of asthma occurred in families where neither parent was affected and the highest prevalence $\vec{x}$ where both parents were affected. Similarly, the prevalence of hay fever/eczema among siblings $\omega$ increased as the number of parents with these $\underset{\omega}{\omega}$ traits increased.

POLAR INTRINSIC PROBANDS

Among the 1166 patients examined, $89(7.6 \%)$ fulfilled the criteria for polar intrinsic asthma. Of $\overparen{\varnothing}$ these, 53 were women. The sex ratio of 0.68 was $\vec{\varphi}$ not significantly different from $1.00 \quad(\mathrm{P}>0.05)$. The prevalence of asthma, hay fcver, and eczema

Table 2 Prevalence of hay fever and eczema among polar extrinsic probands

\begin{tabular}{|c|c|c|c|c|c|c|c|}
\hline \multirow[t]{2}{*}{ Probands } & \multirow[t]{2}{*}{$N$} & \multicolumn{2}{|c|}{ Hay fever only } & \multicolumn{2}{|l|}{ Eczema only } & \multicolumn{2}{|c|}{ Hay fever and eczema } \\
\hline & & No affected & Percent affected & No affected & Percent affected & No affected & Percent affected \\
\hline Men & 164 & 48 & $29 \cdot 3$ & 41 & $25 \cdot 0$ & 35 & $21 \cdot 3$ \\
\hline Women & 163 & 51 & $31 \cdot 3$ & 25 & $15 \cdot 3$ & 49 & $30 \cdot 1$ \\
\hline Total & 327 & 99 & $30 \cdot 3$ & 66 & $20 \cdot 2$ & 84 & $25 \cdot 7$ \\
\hline Significance & & \multicolumn{2}{|c|}{$x^{2}=0.16, P>0.05$} & $x^{2}=3.88, P>0.05$ & & \multicolumn{2}{|c|}{$\mathrm{x}^{2}=2.33, \mathrm{P}>0.05$} \\
\hline
\end{tabular}

Table 3 Prevalence of asthma, hay fever, and eczema among first degree relatives of polar extrinsic probands

\begin{tabular}{|c|c|c|c|c|c|}
\hline Trait & $\begin{array}{l}\text { Prevalence }(\%) \\
\text { Parents }\end{array}$ & Siblings & Offspring & All relatives & $\begin{array}{l}\text { Comparison of parents, } \\
\text { siblings and offspring } \\
\text { Significance }(d f=2)\end{array}$ \\
\hline Asthma & $104 / 654(15 \cdot 9)$ & $70 / 666(10 \cdot 5)$ & $25 / 177(14 \cdot 1)$ & $199 / 1497(13 \cdot 3)$ & $\mathrm{x}^{2}=7 \cdot 19, \mathrm{P}<0.05$ \\
\hline Hay fever & $91 / 654(13 \cdot 9)$ & $69 / 666(10.4)$ & $18 / 177(10 \cdot 2)$ & $178 / 1497(11 \cdot 9)$ & $x^{2}=3.86, P>0.05$ \\
\hline Eczema & $38 / 654 \quad(5 \cdot 8)$ & $45 / 666(6 \cdot 8)$ & $14 / 177 \quad(7 \cdot 9)$ & $97 / 1497 \quad(6 \cdot 5)$ & $x^{2}=1 \cdot 65 . P>0.05$ \\
\hline
\end{tabular}

Table 4 Prevalence of asthma and hay fever/eczema among siblings of extrinsic probands with neither, one, or both parents affected

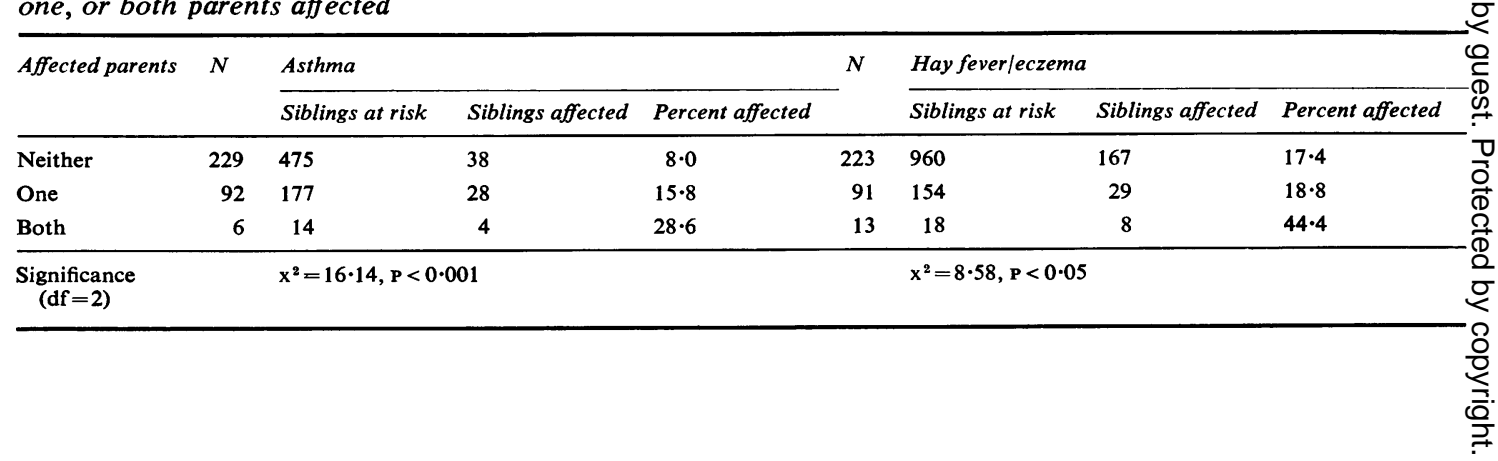


among the first degree relatives of the polar intrinsic probands is summarised in table 5 . The prevalence of asthma was again unevenly distributed among the parents, siblings, and offspring; there were more affected parents and fewer affected siblings than expected.

Sample sizes were too small to permit analysis of the number of affected siblings when neither, one, or both parents had asthma or hay fever/ eczema (table 6). The prevalence of asthma, however, tended to be higher when one parent was asthmatic than when neither parent was affected.

The overall prevalence of asthma among first degree relations of intrinsic probands was significantly lower than that among relatives of extrinsic probands $(P<0.001)$. Similarly, the prevalence of hay fever/eczema was lower among relatives of extrinsic asthmatics $(P<0.001)$.

\section{INTERMEDIATE FORMS OF ASTHMA}

A small number of asthmatic patients who did not fulfil the criteria for polar extrinsic or intrinsic asthma were selected for comparison with the polar groups from the same population. Of the 787 patients attending the Brompton clinic, 22 $(2.8 \%)$ were non-polar intrinsic and $271(34.4 \%)$ were intermediate type. From the latter group 14 randomly selected patients were included in the present study. The prevalence of asthma among relatives of non-polar intrinsic asthmatics was $7 / 96(7.3 \%)$ and that of the intermediate type asthmatics was $10 / 81(12 \cdot 3 \%)$. The prevalence of hay fever or eczema or both was $13 / 95(13.5 \%)$ in the former group and $6 / 81(7 \cdot 4 \%)$ in the latter.
The prevalence of asthma and hay fever/eczema among the first degree relatives of the four groups (for instance, polar intrinsic and extrinsic, nonpolar intrinsics, and intermediate type) is shown (see figure). When the groups of probands are ranked in order of increasing atopy, as assessed by skin test sensitivity, the prevalence of asthma among relatives increases linearly. Between any two adjacent groups of probands, the prevalence of asthma is not significantly different. Between

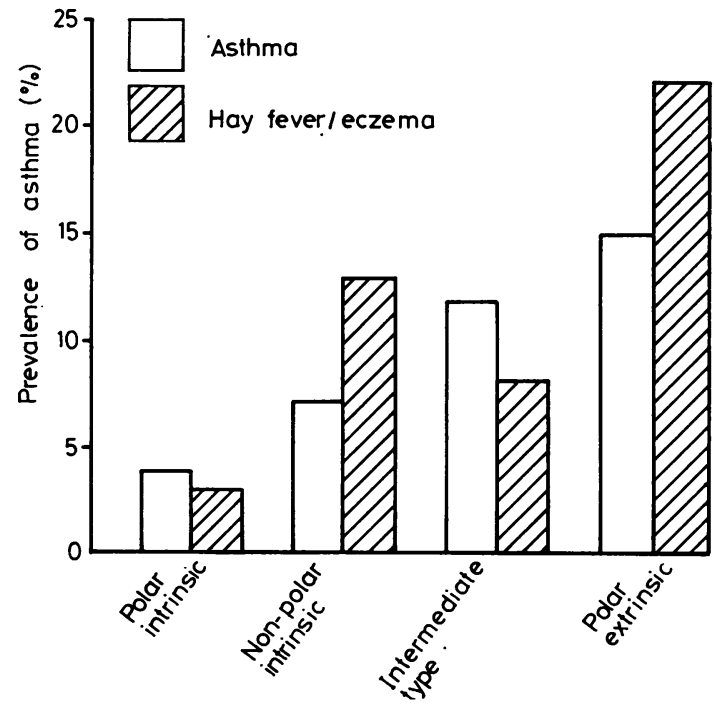

Prevalence of asthma and hay fever/eczema among first degree relatives of probands.

Table 5 Prevalence of asthma, hay fever, and eczema among first degree relatives of polar intrinsic probands

\begin{tabular}{|c|c|c|c|c|c|}
\hline Trait & $\begin{array}{l}\text { Prevalence (\%) } \\
\text { Parents }\end{array}$ & Siblings & Offspring & All relatives & $\begin{array}{l}\text { Comparison of parents, } \\
\text { siblings and offspring } \\
\text { Significance }(d f=2)\end{array}$ \\
\hline Asthma & $14 / 178(7 \cdot 9)$ & $7 / 290(2 \cdot 4)$ & $7 / 158(4 \cdot 4)$ & $28 / 626(4 \cdot 5)$ & $\mathrm{x}^{2}=7 \cdot 27, \mathrm{P}<0.05$ \\
\hline Hay fever & $0 / 178(0)$ & $4 / 290(1 \cdot 4)$ & $6 / 158(3 \cdot 8)$ & $10 / 626(1 \cdot 6)$ & $x^{2}=1 \cdot 67, P>0.05^{*}$ \\
\hline Eczema & $1 / 178(0)$ & $3 / 290(1 \cdot 0)$ & $3 / 158(1 \cdot 9)$ & $7 / 626(1 \cdot 1)$ & $x^{2}=1 \cdot 33, P>0.05$ \\
\hline
\end{tabular}

* Comparison between siblings and offspring $(\mathrm{df}=1)$

Table 6 Prevalence of asthma and hay fever/eczema among siblings of intrinsic probands with neither, one, or both parents affected

\begin{tabular}{|c|c|c|c|c|c|c|c|c|}
\hline \multirow[t]{2}{*}{ Affected parents } & \multirow[t]{2}{*}{$N$} & \multicolumn{3}{|l|}{ Asthma } & \multirow[t]{2}{*}{$N$} & \multicolumn{3}{|c|}{ Hay fever/eczema } \\
\hline & & Siblings at risk & Siblings affected & Percent affected & & Siblings at risk & Siblings affected & Percent affected \\
\hline Neither & 74 & 258 & 4 & $1 \cdot 6$ & 88 & 248 & 13 & $5 \cdot 2$ \\
\hline One & 14 & 32 & 3 & $9 \cdot 4$ & 1 & 4 & 0 & $\mathbf{0}$ \\
\hline Both & 0 & - & 一 & - & $\mathbf{0}$ & - & - & - \\
\hline
\end{tabular}


alternate groups and between the two extremes, however, the differences are significant (polar intrinsic and intermediate type, $\mathbf{P}<0.05$; non-polar intrinsic and polar extrinsic, $\mathrm{P}<0.05$; polar extrinsic and intrinsic $P<0.001$ ).

The prevalence of hay fever/eczema among first degree relatives was also positively correlated with the degree of atopy in the probands (Spearman rank correlation coefficient of $0 \cdot 8$ ).

\section{Discussion}

The Doncaster and Brompton populations were remarkably similar, the sole difference being the relatively higher prevalence of asthma, eczema, and hay fever among relatives of Brompton extrinsic asthmatics than among relatives of Doncaster extrinsic asthmatics. Although the cause of this difference cannot be elucidated in this study, this may reflect a difference in the degree of atopy or the severity or both of the asthma in probands. If Brompton probands were more atopic or more severely affected, their increased predisposition to asthma, eczema, and hay fever might be associated with a higher prevalence of these traits among first degree relatives.

Among extrinsic and intrinsic probands there was no distortion in the sex-ratio and little difference between the sexes in the prevalence of hay fever/eczema. The excess of male extrinsic asthmatics often found in other studies was not observed here. This discrepancy may reflect a bias in ascertainment or may have arisen by chance. In the present study the absence of sexual differences suggests that these traits are neither sexlinked nor sex-influenced.

The increased prevalence of asthma among siblings of probands with one or both parents affected supports the hypothesis that this trait is hereditary. At least part of this familial association, however, may have resulted from a common family environment, which would also tend to increase this prevalence. Similarly the increased prevalence of hay fever/eczema among siblings of probands with one or both parents affected, supports, but does not prove, the concept that atopic manifestations are partly hereditary.

The prevalence of asthma is significantly higher among relatives of extrinsic asthmatics than among relatives of intrinsic asthmatics. Although this difference may result from dissimilarities in the family environments, such that relatives of extrinsic asthmatics are exposed to more environmental provoking factors, it seems more reasonable to suggest that this difference is genetic. If this is true then extrinsic asthmatics have a stronger genetic predisposition to asthma than do intrinsic asthmatics.

It is important to note that this clear separation of the extrinsic and intrinsic populations results from the deliberate selection of highly atopic and clearly non-atopic probands. In practice, most asthmatic patients fall between these two extreme forms of asthma, thus forming a continuous spectrum.

A comparison of the intermediate type of asthma to the two polar forms shows a positive correlation between the prevalence of asthma among first degree relatives and the degree of atopy in the probands (see figure). If we assume that the prevalence of hay fever and eczema provides an estimate of the frequency of atopy, then the prevalence of asthma among relatives is also correlated with the degree of atopy in these same relatives. In addition, the prevalence of asthma and hay fever/eczema is low among relatives of intrinsic asthmatics and high among relatives of extrinsic asthmatics. This strong association between atopy and asthma indicates that atopy may enhance a genetic predisposition to asthma.

The above findings together with the results of previous investigations suggest that the expression of asthma is dependent on (a) genetic factor(s) that predispose individuals to asthma and $(b)$ environmental factor(s) that precipitate asthma in genetically predisposed individuals. Pure environmental or genetic hypotheses may be ruled out since twin and family studies have shown that there is both an environmental and a genetic component to asthma (see introduction for summary).

The particular mode of inheritance of the genetic factor(s) cannot be determined in the present study. The gradual increase in the number of affected siblings with increases in the number of asthmatic parents, however, suggests that asthma may be polygenic. In addition, the excess of affected parents and the slight deficit of affected siblings indicates that one or more of the contributing genes may be recessively inherited.

The results of the present study further suggest that atopy and its manifestations (for instance, hay fever/eczema) may enhance the predisposition $\omega$ to asthma in genetically predisposed individuals. Since atopy is, itself, partly hereditary (Pepys, 1973) relatives of extrinsic asthmatics would then $\mathbb{D}$ inherit a predisposition to asthma as well as an increased likelihood of its being expressed. Hence $T$ the prevalence of both asthma and atopic mani- $\underset{\mathbb{\Phi}}{\stackrel{\circ}{*}}$ festations, such as hay fever and eczema, would be higher among relatives of extrinsic than among $\stackrel{\square}{\Omega}$ relatives of intrinsic asthmatics.

In addition, atopy may lower the age of onset of 
asthma thus giving rise to the characteristically early age of onset in extrinsic asthma. This latter hypothesis is supported by Fepys (1973), who observed a significant negative correlation between age of onset and the degree of atopy in the patient.

We have proceeded to evaluate the hypotheses described above in a population of asthmatic and normal children attending a large general practice. The findings support the conclusions of the present study and will be discussed in detail in a later publication.

We are particularly grateful to Dr Hugh Smyllie and his secretary, Mrs Jean Brodie, for providing the Doncaster data. We also thank Professor J Pepys and Dr J Slack for their valuable advice. During the course of this study, BS was supported by the British Council.

\section{References}

Charpin, J, and Arnaud, A (1971). Facteurs génétiques dans l'asthme et les allergies respiratoires. $L e$ Poumon et le Coeur, 27, 111-119.

Edfors-Lubs, M L (1971). Allergy in 7000 twin pairs. Acta Allergologica, 26, 249-285.
Gregg, I (1977). Asthma, edited by T J H Clark and $\mathrm{S}$ Godfrey, ch 11. Chapman and Hall, London.

Higgins, M, and Keller, J (1975). Family occurence of childhood respiratory disease and familial resemblance in ventilatory capacity. Journal of Chronic Disease, 28, 239-251.

Leeder, S R, Corkhill, R T, Wysocki, M J, Holland, W, and Colley, J R T (1976). Influence of personal and family factors on ventilatory function of children. British Journal of Preventative and Social Medicine, 30, 219-224.

Leigh, D, and Marley, E (1967). Bronchial Asthma, A Genetic, Population and Psychiatric Study. Pergamon Press, Oxford.

Molina, C, Brun, J, Coulet, M, Betail, G, and Delage, J (1977). Immunopathology of the bronchial mucosa in "late onset" asthma. Clinical Allergy, 7, 137-145.

Mulholland, H, and Jones, C R (1968). Fundamentals of Statistics, pp 178-194. Butterworths, London.

Pepys, J (1973). Types of allergic reaction. Clinical Allergy, 3 (suppl), 491-509.

Williams, H E, and McNicol, K N (1969). Prevalence, natural history and relationship of wheezy bronchitis and asthma in children. An epidemiological study. British Medical Journal, 4, 321-325.

Requests for reprints to: Mrs B Sibbald, Department of Medicine, Cardiothoracic Institute, Brompton Hospital, Fulham Road, London SW3. 